\title{
Implications of Interfacial Energetics on the Tack/Debonding of Single and Hybrid Pressure Sensitive Adhesives
}

\author{
${ }^{1}$ Okpe Bernard Okechukwu, ${ }^{* 2}$ Chukwuneke Jeremiah Lekwuwa, ${ }^{2}$ Omenyi Sam Nna \\ ${ }^{1}$ Mechanical Engineering Department IMT Enugu, ${ }^{2}$ Nnamdi Azikiwe University, PMB 5025 Awka, Nigeria
}

\begin{abstract}
This paper present the implications of interfacial energetics on the tack/debonding of pressure-sensitive adhesives (PSA). The materials used include acrylic, pvc-abro, polyurethane and epoxy by single and hybrid combinations. Mild steel plate of $130 \mathrm{~mm}$ x $130 \mathrm{~mm}$ with $1.2 \mathrm{~mm}$ thickness was used as a substrate. The contact angle was measured on surfaces of PSA and the substrate using OWK and Wu models. The force required to debond the PSA from the substrate (the tack) was measured with a universal testing machine. The results gave the maximum deflections as $4.9074 \times 10^{-4} \mathrm{~N} / \mathrm{mm}^{2}$ and tack as $3.35769 \times 10^{-5} \mathrm{~N} / \mathrm{m}$ for single PSA of Epoxy are higher than those for Acrylic, Pvc-Abro and Polyurethane PSAs materials. However, with Acrylic/Epoxy and Epoxy/ Pvc Abro hybrids, higher tack forces of $3 \times 10^{-5} \mathrm{~mJ}$ and $2.725 \times 10^{-5} \mathrm{~mJ}$ with corresponding higher values of $2.28225 \times 10^{-4} \mathrm{~N} / \mathrm{mm}^{2}$ and $1.61243 \times 10^{-4} \mathrm{~N} / \mathrm{mm}^{2}$ maximum deflections were obtained. These results showed that epoxy is better from tack force. The results clearly show that all the properties - surface free energy, work of adhesion, and tack are higher for hybrid PSA than for the single PSAs ranging from $1.5 \%$ to up to $80 \%$ difference. It was observed that as the angle of contact increased, the work of adhesion and cohesion increased. The results of this work can find application in dentistry in dentin/adhesive interface and hybridization of dental hard tissues with modified adhesive systems. Applications can also be found in carpentry, in polymer composites for automobile bodies and ceramics.
\end{abstract}

Keywords: Interfacial energetics; Debonding; adhesives; Contact angle; Epoxy; Substrate; Composite; Automobile

\section{Introduction}

The process of connecting two solids using polymers as adhesives materials shows wide industrial applications. Certain viscoelastic properties allow polymers to fulfil the requirement for their classification as adhesives (Creton, 2003; Carelli et al, 2007). For this purpose, the adhesive has to possess a good combination of two characteristic properties: adhesion and cohesion. Adhesion, or the adhesive's stickiness, is distinguished by low viscosity, compulsory for broad contact area and enhanced bond density (Agirre et al, 2009). Design of adhesives is based on the oriented optimization of the adhesive connection and works successfully both for very small surfaces and for large areas of contact (Pocius, 2002; Ahn et al 2014). The adhesives differ not only by their chemical composition but also by the thermomechanical properties of the bonded joints, processing methods, as well as types of reactions during the bonding. One can categorize them as chemical reacting glues, reactive hot melts, and physical setting glues (Menyo et al, 2013). Cohesion forces represent the sufficient strength of the physical bonds between the polymer molecules to resist externally applied forces. An important advantage of the adhesive joint is the uniform distribution of load over a large area avoiding localization of stress (Aubrey \& Ginosatis, 1999; Charles, 2003).

Contact adhesives are polymers, which show relative high strength after applying a low pressure for short contact time. The process of hardening here is crystallization or diffusion. Pressure-sensitive adhesives (PSA) are soft, viscoelastic solids, based mainly on polymers: acrylics, styrenic block copolymers and natural rubber. Pressure-sensitive adhesives can build a joint by the application of low pressure (Zosel and Barwich, 1995; 
Carelli et al, 2007). This work studies the influence of surface energetics on the tack of different pressuresensitive adhesives, the characteristic property of PSAs to perform this function is called tack (Toyama et al., 1993; Feldstein, 2015). The distinguishing tack properties include low elastic modules, ability to wet adhering surfaces, the cohesive capacity to sustain a minimum level of strength on debonding (Hui et al., 2001; Bledzki et al, 2008 ; Sinebe et al, 2019). Most of the PSAs are polymers as such possess low glass transition temperature, high molecular weight and weak cross-linking. Most testing methods of the tackiness of adhesives were based on the reproduction of test of a thumb adhesive being brought into contact with the substrate and subsequently removed from the adherent surface (Creton et al., 2001). The probe tack test with a flat cylindrical substrate is widely used to test a short-time and low-pressure adhesion. This, however, is also limited to thumb testing.

PSAs are used in the production of protection films in the automotive industry, note pads, labels, masking tapes, analgesic and transdermal drug patches (related with skin contact), and a variety of other products (Benedek and Feldstein, 2009). Studies on PSA did not consider the forces of tacking but centred only on the visible residues on the adherent surface. To avert the problems observed by Feldstein (2009), this work attempts to determine the tack and relating it to the surface free energy, work of adhesion and cohesion. The failure of adhesives holding the ceramic heat shields on the body of Space Shuttle Challenger led to very serious consequences. This work will also seek to determine an alternative to use of single adhesives and the implications of interfacial energetics on the tack of hybrid PSAs.

\section{Materials and Methods}

\subsection{Materials and Preparation}

The pressure-sensitive adhesives (PSA) investigated include Acrylic sealant (mastic Acrylique); PVC Abro; Epoxy; and Polyurethane Adhesives. All were sourced at Kenyatta and Ogbete Market, Enugu, Enugu State, Nigeria. A eight-number substrate material mild steel plate with a near smooth surface and an area of $130 \mathrm{~mm} x$ $130 \mathrm{~mm}$ with a thickness of $12 \mathrm{~mm}$ was used for the test. A Universal testing machine was used for measuring the force at each point of PSA to point of separation from the substrate.

The sample preparation of single PSAs was done for the examination of tackiness using Acrylic, PVC-abro sealant, Epoxy and Polyurethane (Evostick). Hybrid PSAs, comprising of a 50:50 mixture of two PSAs, included Polyurethane/PVC-abro, Acrylic/PVC-abro, Epoxy/Acrylic, Epoxy/Polyurethane and Epoxy/PVCabro respectively. Hybrid PSAs were considered to understand the influence on tack by hybridization. Each sample of PSA was drawn from each container of sample PSA using a syringe of $25 \mathrm{~cm}^{3}$ volume. The drawn samples were deposited on the mild steel plate surface while the other half of the plate was carefully placed on top and allowed to stand for 7days under room temperature before testing commenced. For hybrid PSAs, each sample was also drawn from the container and poured into a dish, while the second was drawn from its container and also poured into the same dish and the 50-50 mixture was blended with the aid of a spatula. The samples for the tests were prepared as stated previously and left to stand for 7 days under $23^{\circ} \mathrm{C}$ room temperature before testing commenced. Each sample was properly labelled according to the mixture type. The plates (mild steel) were thoroughly cleaned with a clean white towel to remove dust and dried under the sun before the PASs was applied. All these were done at the same temperature of $23^{\circ} \mathrm{C}$ and moderate humidity at the Standard Organization of Nigeria (SON) laboratory, Emene Industrial layout Enugu, Nigeria.

\subsection{Methods}

The first set of experiments involved the determination of the force $F$ required to pull apart two flat plates held together by the PSA. The PSA or the adhesive layer was sandwiched in between the two metal plates and mounted on the grip portion of the computerized Universal Testing Machine TUE-C-100 model. The force at which the plates began to separate was recorded as the tack or debonding force, $F$. This was done for single and for hybrid PSAs. This force is a measure of the tack, which is expected to overcome the adhesiveness and better expressed as the tack strength. According to Wang, (2014);

Tack strength $=\left(\frac{F}{b}\right)$ 
Where; $b$ is the width of the adhesive layer. This adhesive strength characterizes the tack force per width of the adhesive layer. The thickness of the adhesive layer is $12 \mathrm{~mm}$ and its width is $130 \mathrm{~mm}$.

The resulting stress-strain and stress-time responses of true stress and true strain of the PSA, recorded by the universal testing machine as the plates were pulled apart were used to calculate the PSA stress deflection $\left(\partial_{\text {max }}\right)$ on materials using the equation (Wang, 2014; Okpe, 2020):

$\left(\partial_{\max }\right)=\frac{F}{A}\left(1+\frac{\Delta l}{l}\right)$

Where $A$ is the area of contact of the adhesive layer on the substrate, $l$ is the length of adhesive.

The next experiment involved the measurement of contact angles of each PSA surface deposited on the mild steel plate. The contact angles so measured were used to calculate the works of adhesion and cohesion.

According to Krevelen \& Nijenhuis, (2009), the specific free surface energy, also known as interfacial energy of a material is the excess energy per unit area due to the existence of the free surface; it is also the thermodynamic work to be done per unit area of surface extension. In PSAs, the specific free surface energy is also called the interfacial energy, since it is equivalent to a line tension acting in all directions parallel to the surface (Sinebe et al, 2019; Chukwuneke et al) is given as;

$\gamma_{s}=\frac{\text { Work }}{\text { Area }}$

Where; $\mathrm{W}=$ Force $\mathrm{x}$ distance

The work of adhesion is given by;

$W_{A}=\gamma_{S}+\gamma_{L}-\gamma_{S L}$

When combined with Young's equation, gives;

$W_{A}=\Upsilon_{L}(1+\operatorname{Cos} \theta)$

According to Leger and Creton 2007 work done on a PSA is expressed as 0.001F which is constant.

The work of cohesion of one substrate is expressed as

$W_{C}=\gamma_{A}+\gamma_{A}-0=2 \gamma_{A}$

Eqs. (1) to (6) was used, together with experimental data to calculate the relevant quantities.

\section{Results and Discussion}

The results of calculated tack force $\left(F_{\text {tack }}\right)$, of every single sample which is the force per width of the adhesive layer from the measured area of the plate and the maximum deflection $\left(\partial_{\max }\right) \mathrm{N} / \mathrm{mm}^{2}$ are given in table (1).

Table 1: Tack/Debonding Force on Maximum Deflection and Calculated Tack of Single PSAs.

\begin{tabular}{|l|c|c|c|c|}
\hline \multicolumn{1}{|c|}{ Sample } & $\begin{array}{c}\text { Area, } A \\
\mathrm{~m}^{2}\end{array}$ & $\begin{array}{c}\text { Force, } F \\
(\mathrm{~N})\end{array}$ & $\begin{array}{c}\text { Max. stress deflection } \\
\left(\partial_{\max }\right) \mathrm{N} / \mathrm{m}^{2}\end{array}$ & $\begin{array}{c}\text { Calculated tack } \\
\text { strength }\left(F_{\text {tack }}\right) \mathrm{N} / \mathrm{m}\end{array}$ \\
\hline Acrylic & 0.0169 & 0.00000111 & 0.000124793 & $8.53846 \mathrm{E}-06$ \\
\hline Epoxy & 0.0169 & 0.000004365 & 0.00049074 & $3.35769 \mathrm{E}-05$ \\
\hline Pvc Abro & 0.0169 & 0.000001715 & 0.000192811 & $1.31923 \mathrm{E}-05$ \\
\hline Polyurethane & 0.0169 & 0.000001745 & 0.000196183 & $1.34231 \mathrm{E}-05$ \\
\hline Average & 0.0169 & 0.000002234 & 0.0002511 & $0.1718 \mathrm{E}-05$ \\
\hline
\end{tabular}


Table 1 showed that with Epoxy of $4.365 \times 10^{-6} \mathrm{~N}$ force, both maximum deflection and calculated force depicted the highest values of $4.9074 \times 10^{-4} \mathrm{~N} / \mathrm{m}^{2}$ and $3.35769 \times 10^{-5} \mathrm{~N} / \mathrm{m}$. Also, with the lower force of $1.11 \times 10^{-6} \mathrm{~N}$ by Acrylic, the values of maximum and calculated force were equally least at $1.24793 \times 10^{-6} \mathrm{~N} / \mathrm{m}^{2}$ and $8.53846 \times 10^{-}$ ${ }^{6} \mathrm{~N} / \mathrm{m}$. This suggests that as a tack or deboning forces increase in peeling of pressures sensitive adhesives materials from the substrate, it leads to resultant increment with maximum deflection and calculated tack. Consequently, in PSA materials, the maximum deflections and calculated tack forces are better achieved with Epoxy materials than Acrylic, Pvc-Abro and Polyurethane PSAs materials which infer better bonding forces.

The results of PSA samples of maximum deflection and calculated tack force $\left(F_{\text {tack }}\right)$, of acrylic mixed (pvc-abro, polyurethane and epoxy) and hybrid epoxy with (acrylic, pvc-abro and polyurethane) by contact angle model are given in table (2). Figure (1) represents the effect of tack/debonding forces on the maximum deflection of Hybrid PSA samples.

Table 2: Tack/ Debonding Force of Hybrid by Contact Angle Model

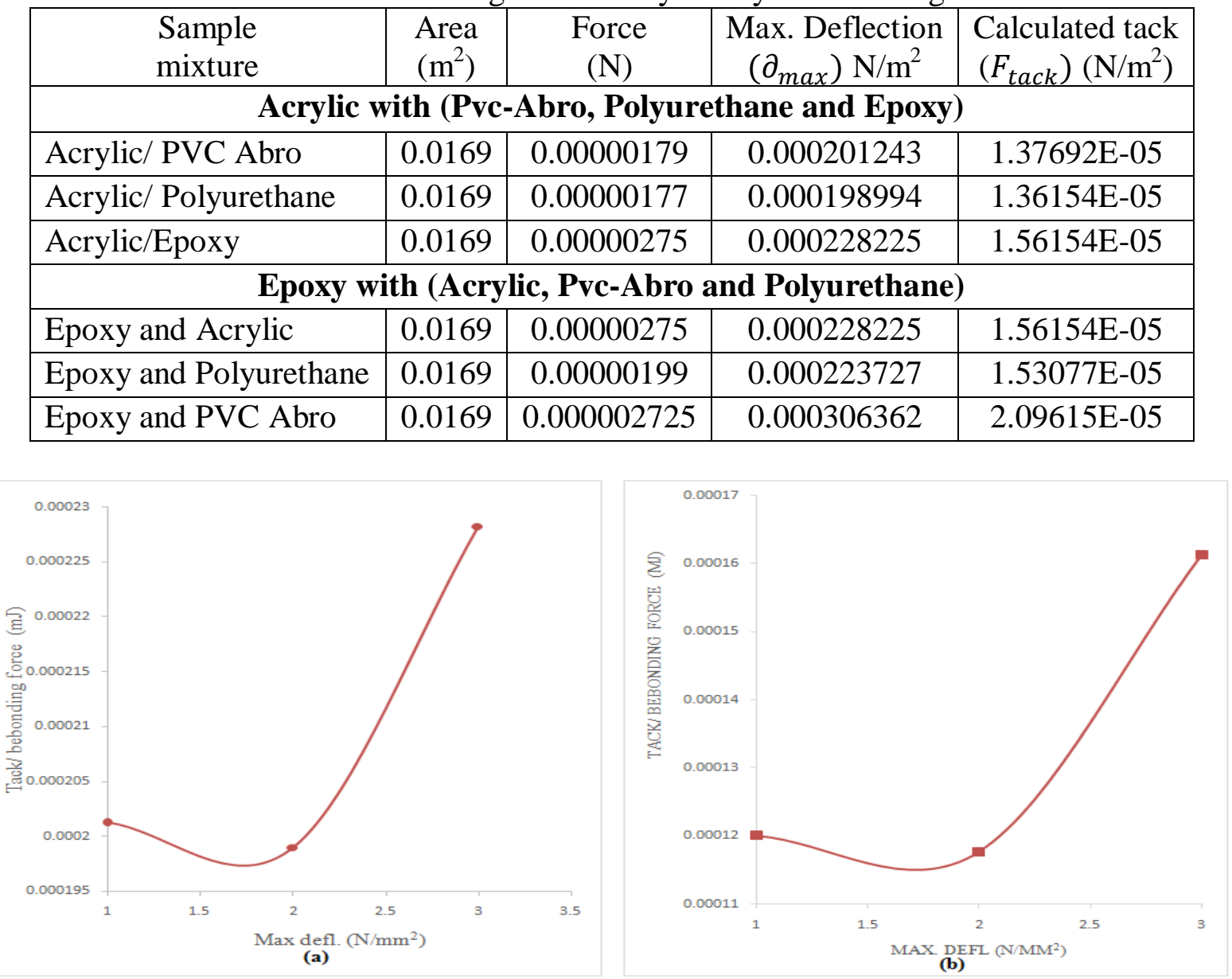

Figure 1: Effect of Tack/ Debonding Force on a maximum deflection by Contact Angle Model (a) Hybrid Acrylic with (Pvc-Abro, Polyurethane and Epoxy) (b) Epoxy Mixed (Acrylic, Pvc-Abro and Polyurethane)

Figure (1) show that hybrids of Acrylic/Epoxy and Epoxy/ Pvc Abro have higher tack/debonding forces of $3 \times 10^{-5} \mathrm{~N}$ and $2.725 \times 10^{-5} \mathrm{~N}$ with corresponding higher values of $2.28225 \times 10^{-4} \mathrm{~N} / \mathrm{m}^{2}$ and $3.06362 \times 10^{-4} \mathrm{~N} / \mathrm{m}^{2}$ maximum deflections. The least occurred Acrylic/ Polyurethane, and Epoxy and Polyurethane of tack forces of $1.77 \times 10^{-5} \mathrm{~N}$ and $1.989 \times 10^{-5} \mathrm{~N} / \mathrm{m}^{2}$ with equivalent $1.99 \times 10^{-4} \mathrm{~N}$ and $2.23727 \times 10^{-4} \mathrm{~N} / \mathrm{m}^{2}$ maximum deflections. This showed that the pressure-sensitive materials have better tack/debonding forces with corresponding maximum deflection when they are mixed (in hybrid) by Acrylic/ Polyurethane, and/or Epoxy and Polyurethane.

Figure (2) show the effect of tack/debonding forces on maximum deflection and calculated tack of hybrid acrylic/epoxy on the other samples. 


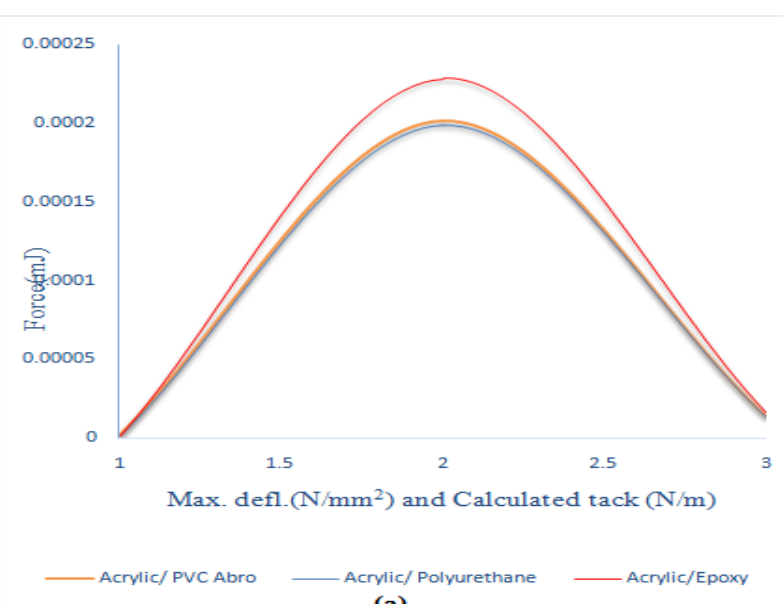

(a)

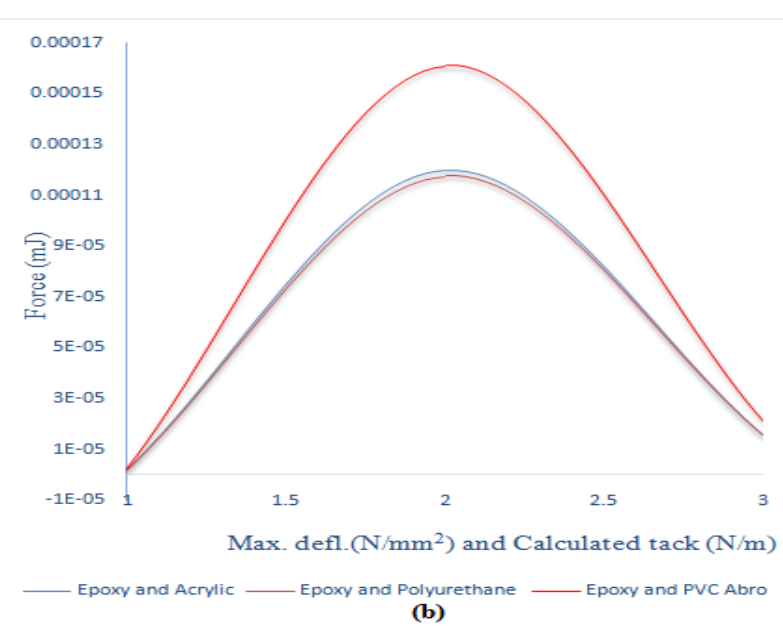

(b)

Figure 2: Effect of tack/debonding on Maximum Deflection and Calculated tack (a) Hybrid Acrylic with (PvcAbro, Polyurethane and Epoxy) (b) Epoxy Mixed (Acrylic, Pvc-Abro and Polyurethane)

Figure (2) show that Acrylic/Epoxy and Epoxy/ Pvc Abro mixed (hybrid) have higher tack/debonding forces of $3 \times 10^{-5} \mathrm{~mJ}$, this also resulted to increased values of $2.28225 \times 10^{-4} \mathrm{~N} / \mathrm{mm}^{2}$ and $1.61243 \times 10^{-4} \mathrm{~N} / \mathrm{mm}^{2} \mathrm{maximum}$ deflections with the corresponding calculated tacks of $1.56154 \times 10^{-5} \mathrm{~N} / \mathrm{m}$ and $2.09615 \times 10^{-5} \mathrm{~N} / \mathrm{m}$ respectively. This shows that the mixture of Acrylic/Epoxy and Epoxy/ Pvc Abro PSA materials can withstand higher shock incase a force is applied to it without damage. It is equally suggested that the bonding on the substrate materials is better achieved when there is a blend of Acrylic/Epoxy and/or Epoxy/ Pvc Abro. The trend is deduced as Acrylic/Epoxy to Pvc-Abro to Polyurethane and Epoxy/Pvc-Abro to Acrylic and Polyurethane on maximum deflections and calculated tacks of PSAs.

Table (3) shows the free energy of angle of contact with works of Adhesion by the Contact angle, OWK and $\mathrm{Wu}$ models.

Table 3: Free Energy of Angle of Contact with Works of Adhesions by Contact Angle, OWK and Wu models.

\begin{tabular}{|l|l|l|l|l|}
\hline Samples & Acrylic & Expoxy & PVC Abro & Polyurethane \\
\hline$\left.\Upsilon_{L}(\mathrm{~N} / \mathrm{m}) \times 10^{-3}\right)$ & 0.00657 & 0.25828 & 0.10148 & 0.10325 \\
\hline Angle of Contact $\theta\left({ }^{\circ} \mathrm{C}\right)$ & 86.64 & 89.15 & 87.83 & 87.87 \\
\hline Wa $($ Contact Model $)\left(\mathrm{mJ} / \mathrm{m}^{2}\right)$ & $6.95293 \mathrm{E}-05$ & 0.000262 & 0.000105325 & 0.000107096 \\
\hline Wa $($ OWK Model $)\left(\mathrm{mJ} / \mathrm{m}^{2}\right)$ & 23.83 & 23.622 & 23.83 & 23.622 \\
\hline Wa $(\mathrm{Wu}$ Model $)\left(\mathrm{mJ} / \mathrm{m}^{2}\right)$ & 8 & 8 & 8 & 8 \\
\hline
\end{tabular}

Table (3) reveals that at the lowest value of angle of contact of $86.64^{\circ} \mathrm{C}$, the work of adhesion by OWK, model showed the highest work of adhesion of $23.83 \mathrm{~mJ} / \mathrm{m}^{2}$. This was observed in acrylic and pvc-abro. Besides, the work of $\mathrm{Wu}$ model showed a constant value of $8 \mathrm{~mJ} / \mathrm{m}^{2}$ irrespective of the angle of contact. However, the works of adhesion of Contact angle model were least irrespective of the values of contact angles. This showed that the work of adhesion by OWK is higher and the least is with Contact angle model, with constant values in Wu model. Despite the difference in surface free energy of the interfacial force of each sample, all the samples showed the same trend in the work of adhesion. The smaller surface free energy was recorded with acrylic of $6.58 \times 10^{-5} \mathrm{~mJ} / \mathrm{m}^{2}$. It was highest at $23.83 \times 10^{-5} \mathrm{~mJ} / \mathrm{m}^{2}$ with $\mathrm{OWK}$ model, followed by $6.94 \times 10^{-5} \mathrm{~mJ} / \mathrm{m}^{2}$ for $\mathrm{Wu}$ model. Correspondingly, this trend was repeated in epoxy, pvc-abro and polyurethane. Similarly, irrespective of the difference in surface free energy, the work of adhesion by Wu model showed a constant $8 \mathrm{~mJ} / \mathrm{m}^{2}$.

Figure (3) shows the surface free energy with the work of adhesion and cohesion for the same sample of contact angle model. 

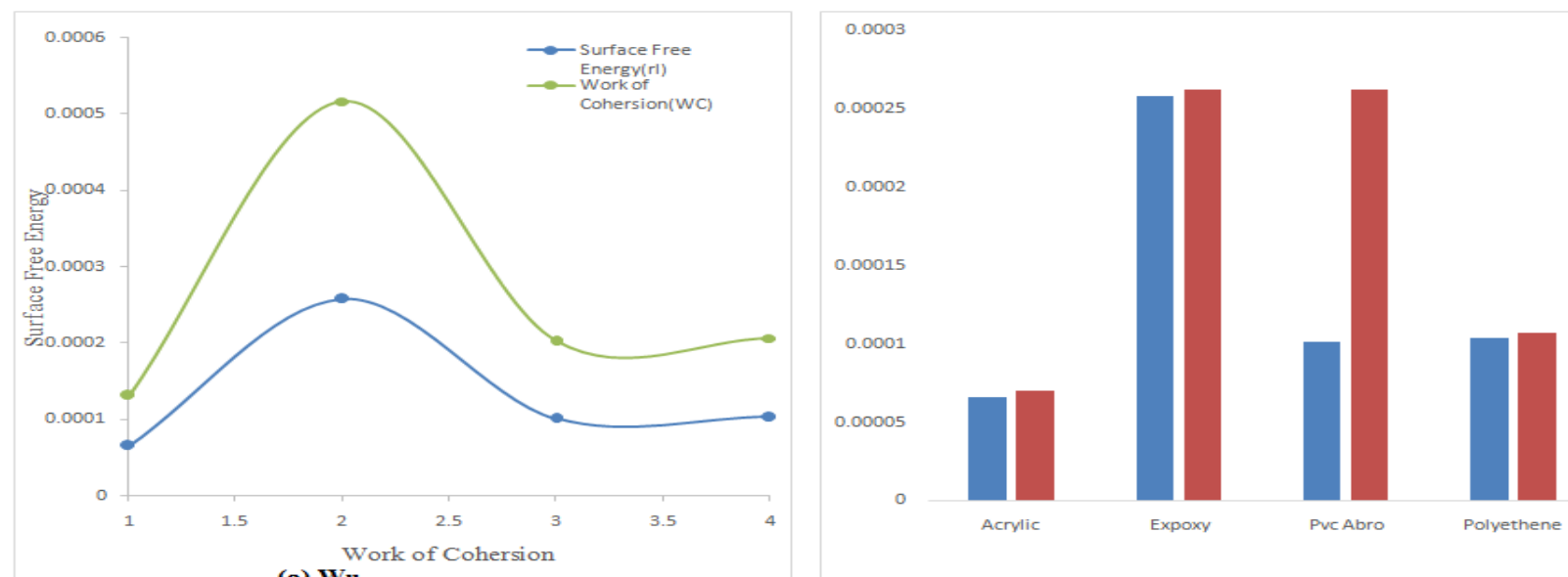

$\mathbf{W u}$

$\begin{array}{lll}-Y L=F / A & \text { m work of cohension } & \text { (b) OWK }\end{array}$

Figure 3: Surface free energy with the work of adhesion and cohesion for the same sample of contact Angle model.

Figure (3) presents the Surface free energy with the work of cohesion for the same sample of contact angle model. It shows that the work of cohesion of tested pressure-sensitive additives is higher than the surface free energy. The maximum value of work of cohesion by Wu model was observed at epoxy of $6.166 \times 10^{-4} \mathrm{~mJ} / \mathrm{m}^{2}$ and lowest at acrylic of $1.336 \times 10^{-4} \mathrm{~mJ} / \mathrm{m}^{2}$. It was deduced that from the samples of pressure-sensitive adhesives testes, work of cohesion is better achieved with acrylic, epoxy and polyurethane. Conversely, the work of cohesion is better achieved with pvc-abro for ease bonding for pressure-sensitive material productions.

The pressure tested adhesives are of different mix analyzed with the three models used. Table (4) shows work of Adhesion and Cohesion with Angle of Contact in Epoxy, Acrylic Mix. The samples used to obtain the work of adhesion and cohesion by the angle of contact.

Table 4: Contact Angle data and Work of Adhesion and Cohesion for Epoxy, Acrylic Hybrid

\begin{tabular}{|l|l|l|l|}
\hline Sample Mixtures & $\theta(\mathrm{deg})$ & $\begin{array}{l}\text { Work of Adhesion } \\
W_{A}\left(\mathrm{~mJ} / \mathrm{m}^{2}\right) \times 10^{-4}\end{array}$ & $\begin{array}{l}\text { Work of Cohesion } \\
W_{C}\left(\mathrm{~mJ} / \mathrm{m}^{2}\right) \times 10^{-4}\end{array}$ \\
\hline Epoxy and Acrylic & 88.20 & 1.239 & 2.402 \\
\hline Epoxy and Polyurethane & 88.10 & 1.216 & 2.355 \\
\hline Epoxy and PVC Abro & 88.93 & 1.642 & 3.225 \\
\hline Acrylic/ PVC Abro & 87.92 & 1.100 & 2.118 \\
\hline Acrylic/ Polyurethane & 87.89 & 1.085 & 2.095 \\
\hline Acrylic/Epoxy & 88.20 & 1.240 & 2.402 \\
\hline Average & 88.21 & 1.254 & 2.433 \\
\hline
\end{tabular}

It was observed from the table (4) that the higher the angle of contact, the higher work of adhesion and cohesion. This is evident at the point where the angle of contact was $88.93 \mathrm{deg}$ for epoxy and pvc-abro mixed. The corresponding work of adhesion and cohesion forces is $3.225 \mathrm{~mJ} / \mathrm{m}^{2}$ and $1.642 \mathrm{~mJ} / \mathrm{m}^{2}$. It was inferred that as the angle of contact increases, the work of adhesion and cohesion increases. This assists in the better pressure-sensitive adhesive in cohesive and adhesive bonding. It showed for effective bonding, the angle of contact should be higher.

The percentage results of all the works of adhesion for the three techniques are summarized in table (5).

Table 5: Comparative Results of SFE of Adhesion by CA, OWK and WU Models of Pressure Sensitive Adhesives

\begin{tabular}{|l|l|l|l|}
\hline Material Mixtures & $\begin{array}{l}\text { Work of adhesion } \\
\text { by CA Model (\%) }\end{array}$ & $\begin{array}{l}\text { Work of Adhesion } \\
\text { by OWK Model (\%) }\end{array}$ & $\begin{array}{l}\text { Work of Adhesion by } \\
\text { Wu Model (\%) }\end{array}$ \\
\hline Epoxy and PVC- Abro & 1.83 & & 83.9 \\
\hline Epoxy and Acrylic & 3.28 & & 88.0 \\
\hline
\end{tabular}




\begin{tabular}{|l|l|l|l|}
\hline Mean Value difference & $\mathbf{2 . 5 6}$ & & $\mathbf{8 5 . 9 5}$ \\
\hline Acrylic and PVC-Abro & 9.38 & 73.8 & \\
\hline Acrylic and Epoxy & 30.21 & 71.73 & \\
\hline Mean Value difference & $\mathbf{1 9 . 8 0}$ & $\mathbf{7 2 . 7 6}$ & \\
\hline
\end{tabular}

From table (5), the work of the OWK model does not have a constant value unlike in work of adhesion in Wu model. However, acrylic and pvc-abro mix showed $9.38 \%$ difference surface free energy work of adhesion by contact angle as against $73.89 \%$ value of work of adhesion by OWK model of the same acrylic and pvc-abro mixed. Similarly, acrylic and epoxy mixed recorded $30.21 \%$ difference surface free energy of adhesion work by contact angle model as against $71.73 \%$ value by OWK model of the same mixed. The mixture of epoxy and pvc-abro of the table (5) shows a percentage mean value of $2.56 \%$. Also, the mixture of acrylic and pvc-abro; for acrylic-epoxy recorded $19.80 \%$ mean value, for the contact angle model. However, the models of work of adhesion by Wu and OWK showed $85.95 \%$ and $72.76 \%$ respectively. In the contact angle model used in both mixtures for work of adhesion, it showed that the lower the percentage mixture of $2.56 \%$ occurred with epoxy mixed, while a higher percentage of $19.80 \%$ was recorded using acrylic mixed. This inferred that the lower the percentage value of work of adhesion using epoxy by contact angle model, the better the tack, but the higher the percentage mixed using work of adhesion using acrylic of Wu model, the higher tack. In the same vein, the higher the percentage mixed using acrylic, as recorded by work of adhesion by contact angle model the lower the tack. Correspondingly, the lower the percentage mixed using OWK model, the better the work of adhesion in the same mixed.

Similarly, Table (6) shows the Surface Free Energy Work of Adhesions in Acrylic Mix Using Contact Angle and $\mathrm{Wu}$ Models.

Table 6: Surface Free Energy Work of Adhesions in Acrylic Mix (Hybrid) using Contact Angle and Wu Models

\begin{tabular}{|l|c|c|c|}
\hline \multicolumn{1}{|c|}{ Sample mixture } & $\begin{array}{c}\Upsilon_{L}=\mathrm{W} / \mathrm{A} \\
\left(\mathrm{mJ} / \mathrm{m}^{2}\right) \times 10^{-4}\end{array}$ & $\begin{array}{c}\text { Work of Adhesion } \\
\left(\mathrm{mJ} / \mathrm{m}^{2}\right) \times 10^{-4} \\
\text { CA Method }\end{array}$ & $\begin{array}{c}\text { Work of Adhesion } \\
\left(\mathrm{mJ} / \mathrm{m}^{2}\right) \times 10^{-4} \\
\text { Wu Method }\end{array}$ \\
\hline Epoxy and Acrylic & 1.2 & 1.24 & 10 \\
\hline Epoxy and Polyurethane & 1.18 & 1.22 & 10 \\
\hline Epoxy and PVC Abro & 1.61 & 1.64 & 10 \\
\hline
\end{tabular}

From table (6), Wu model for work of adhesion in epoxy mixed showed a constant value of $10 \mathrm{~mJ} / \mathrm{m}^{2}$ surface free energy. However, epoxy and pvc-abro mix showed a lower value of $1.83 \%$ for contact angle model as against $83.9 \%$ value by $\mathrm{Wu}$ model of surface free energies. Imperatively, epoxy and acrylic showed higher values percentage increment of $3.23 \%$ by contact angle model and $88 \%$ by Wu model of the same epoxy acrylic mixed.

In the same way, figure (4) shows both the acrylic and epoxy mixed with other materials. 


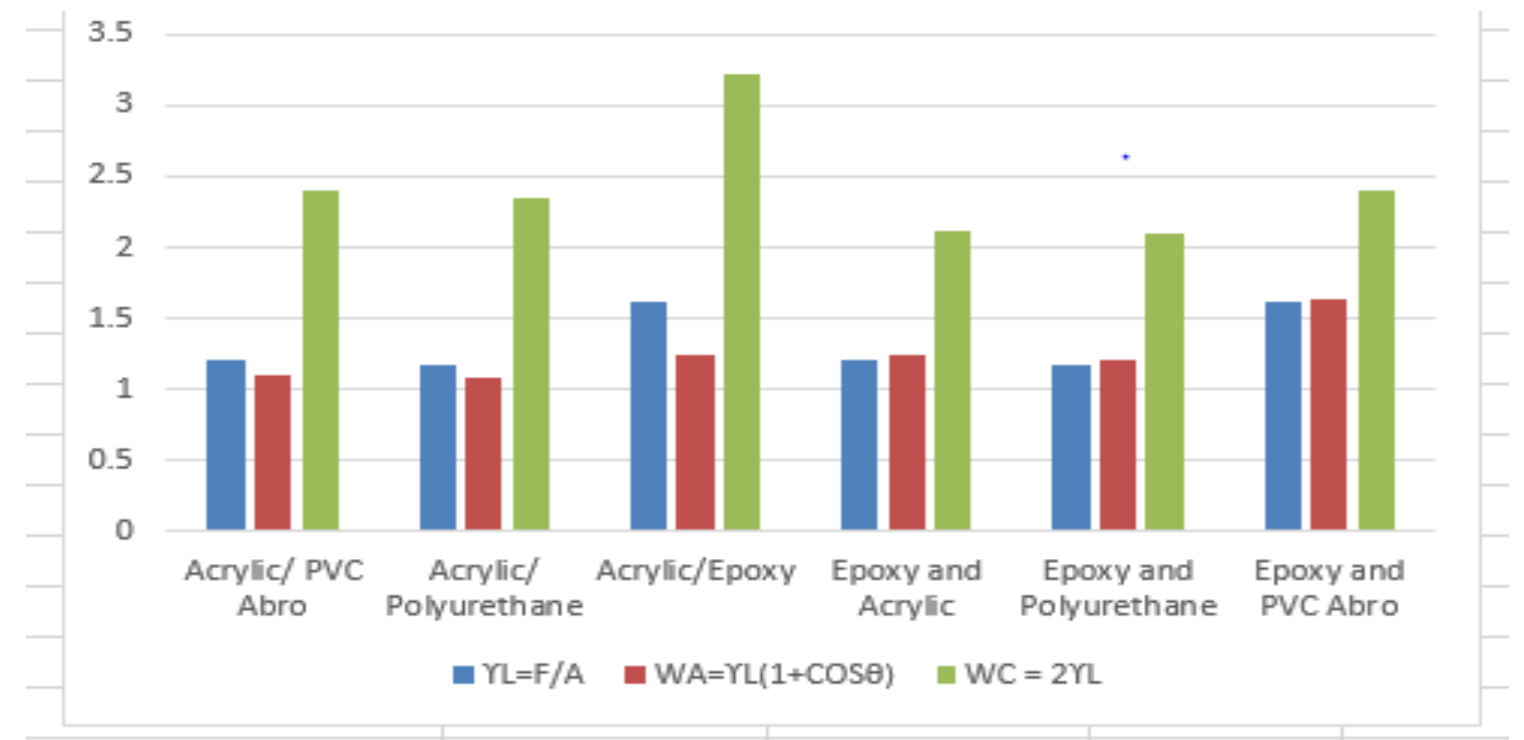

Figure 4: Work of Adhesion and Cohesion with Surface Free Energy in Acrylic and Epoxy Hybrid

Figure (4) shows that the higher the surface free energy, the higher the work of cohesion with lower work of adhesion, except for work of adhesion in all epoxy mixed that moved a little above work of adhesion by 1.239 $\mathrm{mJ} / \mathrm{m}^{2}, 1.217 \mathrm{~mJ} / \mathrm{m}^{2}$ and $1.64 \mathrm{~mJ} / \mathrm{m}^{2}$, with corresponding surface free energies of $1.20 \mathrm{~mJ} / \mathrm{m}^{2}, 1.17 \mathrm{~mJ} / \mathrm{m}^{2}$ and $1.612 \mathrm{~mJ} / \mathrm{m}^{2}$ respectively. This showed that for acrylic mixed, that work of cohesion is higher than surface free energy. Conversely, surface free energy is higher than the work of adhesion. Additionally, in epoxy mixed, work of cohesion is higher than surface free energy, but the work of adhesion is slightly higher than surface free energy.

\section{Conclusion}

This study involved the implications of interfacial energetics on the tack/debonding pressure-sensitive adhesives of Acrylic, PVC- abro. Epoxy and Polyurethane based on the thermodynamic modelling of work of adhesion and cohesion with three different techniques. With the same Epoxy, The tack or deboning forces increased in peeling of pressures sensitive adhesives materials from the substrate, it leads to resultant increment with maximum deflection and calculated tack. Consequently, in PSA materials, the maximum deflections of 4.9074 $\mathrm{x} 10^{-4} \mathrm{~N} / \mathrm{mm}^{2}$, and calculated tack forces of $3.35769 \times 10^{-5} \mathrm{~N} / \mathrm{m}$ are better achieved with Epoxy materials than Acrylic, Pvc-Abro and Polyurethane PSAs materials which inferred better bonding forces. The pressuresensitive materials have better tack/debonding forces with corresponding maximum deflection when they are mixed with Acrylic/ Polyurethane, and/or Epoxy and Polyurethane.

The hybrid of Acrylic/Epoxy and Epoxy/ Pvc Abro PSA materials can withstand higher shock incase a force is applied to it without damage. The trend is deduced as Acrylic/Epoxy to Pvc-Abro to Polyurethane and Epoxy/Pvc-Abro to Acrylic and Polyurethane on maximum deflections and calculated tacks of PSAs. Besides, the works of adhesion of Contact angle method was least irrespective of the values of angles contact. This showed that the work of adhesion by OWK is higher and the least is with Contact angle method, with constant values in $\mathrm{Wu}$ method using acrylic and pvc-abro. This showed that irrespective of the difference in surface free energy, the work of adhesion by $\mathrm{Wu}$ method showed a constant $8 \mathrm{~mJ} / \mathrm{m}^{2}$. The maximum value of work of cohesion by $\mathrm{Wu}$ method was observed at epoxy of $6.166 \times 10^{4} \mathrm{~mJ} / \mathrm{m}^{2}$ and lowest with acrylic of $1.336 \times 10^{-}$ ${ }^{4} \mathrm{~mJ} / \mathrm{m}^{2}$. It was deduced that from the samples of pressure-sensitive adhesive testes, work of cohesion is better achieved with acrylic, epoxy and polyurethane. Conversely, the work of adhesion is better achieved with pvcabro for ease bonding for pressure-sensitive material productions. Hybrid Acrylic and pvc-abro mix showed $9.38 \%$ difference surface free energy of work of adhesion by contact angle as against $73.89 \%$ value of work of adhesion by OWK method of the same acrylic and pvc-abro mixed. Hybrid Epoxy and pvc-abro mix showed a lower value of $1.83 \%$ for the contact angle method as against $83.9 \%$ value by Wu method of surface free 
energies. Imperatively, epoxy and acrylic showed higher values percentage increment of $3.23 \%$ by contact angle method and $88 \%$ by Wu method of the same epoxy acrylic mixed.

It was deduced that work of cohesion is better achieved with acrylic, epoxy and polyurethane. Conversely, the work of adhesion is better achieved with pvc-abro for ease bonding for pressure-sensitive material productions. It was inferred that as the angle of contact increases, the work of adhesion and cohesion increases. This assisted in better pressure-sensitive adhesives in cohesive and adhesive bonding. It showed for effective bonding, the angle of contact should be higher. The average mean value of tack was $0.0170 \mathrm{~N} / \mathrm{m}$ and the work of adhesion was $135.875 \mathrm{~mJ} / \mathrm{m}^{2}$. This is in line with a dominant contribution to the tack resistance force as noted by Benedek and Feldstein (2009) where the condition of peeling tack force is $0.0055 \mathrm{~N} / \mathrm{m}$ to $0.325 \mathrm{~N} / \mathrm{m}$ with a range of adhesion works of 50 to $180 \mathrm{~mJ} / \mathrm{m}^{2}$ for a strong dependence on test conditions. It has been effectively shown that bonding and debonding of adhesives on substrates can be understood using interfacial energetics principles. This study has shown that the work of adhesion, a surface energetic variable, can be related to tack and the debonding of pressure-sensitive adhesives. This work will find its usefulness in the adhesives industry, in carpentry, in dentistry, in polymer composites design and production and in a host of other applications where two or more materials need to be joined together with adhesives.

\section{References}

[1] Agirre M., Nase J., Creton C., Asua J. M. (2009). Adhesives for Low-Energy Surfaces.

[2] Macromolecular Symposia, 281: 181 - 190.

[3] Ahn B.K., Lee D.W., Israelachvii J.N., Waite J.H. 2014. Surface-initiated self-healing of polymers in Aqueous Media. Nature Materials, 13(9): 867 - 872.

[4] Aubrey, D.W. and Ginosatis, S. 1999. Peel Adhesion Behavior of Carboxylic Elastomers. J. Adhes., 12, 189-198.

[5] Bledzki, A., Al-Mamun, A., Lucka-Gabor, M.M., Gutowski, V. 2008. The effects of acetylation on properties of flax fibre and its polypropylene composites. eXPRESS Polymer Letters, 2: 413-422. 10.3144/expresspolymlett.2008.50.

[6] Benedek, I. and Feldstein M. M. 2009. Fundamentals of Pressure-Sensitivity. Handbook of Pressure Sensitivity Adhesion and Products, Benedek I. Ed. Taylor \& Francis, Boca Raton. Vol. 3.

[7] Carelli C.; Deplace F.; Boissonnet L. and Creton C. 2007. Effect of a Gradient in Viscoelastic Properties on the Debonding Mechanisms of Soft Adhesives. J. Adhes, 83: 491 - 505.

[8] Charles E. C. 2003. Polymer Chemistry. $6^{\text {th }}$ Ed. Revised and Expanded. Marcel Dekker, Inc. NY.

[9] Chukwuneke JL, Achebe CH, Omenyi SN. 2015. Surface Thermodynamics Approach to Mycobacterium Tuberculosis (M-tb)-Human Sputum Interactions. Journal of Bioengineering \& biomedical Science, 5(3): 167.

[10] Creton C., Hooker J. and Shull K. R. 2001. Bulk and Interfacial Contributions to the Debonding Mechanisms of Soft Adhesives: Extension to Large Strains. Langmuir, 17: 4948 - 4954.

[11] Creton, C. (2003). Material Science of Adhesives: How to Bond Things Together. Mrs Bulletin.,

[12] 28(6): $419-423$.

[13] Feldstein M. M. (2009). Molecular Nature of Pressure-Sensitive Adhesives, in Fundamentals of Pressure-Sensitivity Adhesion, in Development in Pressure-Sensitive Products, Benedek I. Ed., Taylor \& Francis, Boca Raton, Chapter 10.

[14] Feldstein M. M., Elena E. D., Alexei R. K. 2015. Pressure-sensitive adhesives based on interpolymer complexes. Progress in Polymer Science, 42: 79 - 153.

[15] Hui C. Y., Lin Y. Y., Baney J. M. and Kramer E. J. (2001). The Mechanics of Contact and Adhesion of Periodically Rough Surfaces. J. Polym. Sci., Part B: Polym. Phys., 39: 1195 - 1214.

[16] Krevelen, D.W. \& Nijenhuis, K. 2009. Interfacial Energy Properties: Their Correlation with Chemical Structure. $4^{\text {th }}$ Completely Rev. Ed. 10.1016/B978-0-08-054819-7.00008-X.

[17] Leger L. and Creton C. 2007. Adhesion Mechanisms at Soft Polymer Interfaces. Phil. Trans. R. Soc. A., 366: 425 - 1442.

[18] Menyo, M. S., Hawker, C. J. \& Waite, J. H. 2013. Versatile tuning of supramolecular hydrogels through metal complexation of oxidation-resistant catechol-inspired ligands.Soft Matter.9,10314-10323. 
[19] Okpe Bernard Okechukwu (2020). Implications of Interfacial Energetics on the Tack/Debonding of Single and Hybrid Pressure Sensitive Adhesives. Nnamdi Azikiwe University, Awka, Nigeria. PhD Thesis.

[20] Pocius A.V. 2002. Adhesion and Adhesive Technology: An Introduction. $3^{\text {rd }}$ Ed. Hanser Publishers, Munich.

[21] Sinebe, J. E., Chukwuneke J. L., Omenyi S. N. 2019. Implications of Interfacial Energetics on Mechanical Strength of Fiber Reinforced Polymer Matrix. Int. J. Mats. Eng., 9(1): 1 - 7.

[22] Sinebe, J. E., Chukwuneke J. L., Omenyi S. N. 2019. Surface Energetics Effects on Mechanical Strength of Fiber Reinforced Polymer Matrix. J. Phys.: Conf. Ser., 1378:042016.

[23] Toyama M., Ito T., Nukatsuka H. and Ikeda M. 1993. Studies on Tack of Pressure Sensitive Adhesive Tapes: On the Relationship between Pressure-Sensitive Adhesion and Surface Energy of Adherends. $J$. Appl. Polym. Sci. vol. 17, pp. 3495-3502.

[24] Wang Yue. 2014. The effect of peeling rate and peeling angle on the Peeling Strength. The University of Akron, MSc Thesis.

[25] Zosel, A. and Barwich, J. 1995. Mechanical Properties and Adhesion Performance of UV Cross Linkable Hot Melt Pressure Sensitive Adhesives. PSTC Pressure Sensitive Adhesive Tape. Conf. Proc. Orlando. 175-87. 